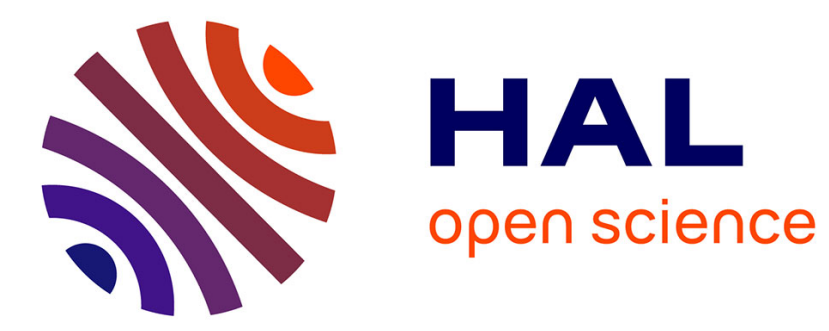

\title{
CRITICAL STUDIES OF MOLECULAR REORIENTATION IN ORIENTED PAA WITH VARIOUS KINDS OF DEUTERATION
}

\author{
J. Janik, J. Krawczyk, K. Otnes
}

\section{> To cite this version:}

J. Janik, J. Krawczyk, K. Otnes. CRITICAL STUDIES OF MOLECULAR REORIENTATION IN ORIENTED PAA WITH VARIOUS KINDS OF DEUTERATION. Journal de Physique Colloques, 1979, 40 (C3), pp.C3-169-C3-173. 10.1051/jphyscol:1979334 . jpa-00218730

HAL Id: jpa-00218730

https://hal.science/jpa-00218730

Submitted on 1 Jan 1979

HAL is a multi-disciplinary open access archive for the deposit and dissemination of scientific research documents, whether they are published or not. The documents may come from teaching and research institutions in France or abroad, or from public or private research centers.
L'archive ouverte pluridisciplinaire HAL, est destinée au dépôt et à la diffusion de documents scientifiques de niveau recherche, publiés ou non, émanant des établissements d'enseignement et de recherche français ou étrangers, des laboratoires publics ou privés. 


\title{
CRITICAL STUDIES OF MOLECULAR REORIENTATION IN ORIENTED PAA WITH VARIOUS KINDS OF DEUTERATION
}

\author{
J. A. JANIK and J. KRAWCZYK \\ Institute of Nuclear Physics, 31-342 Kraków, Poland
}

J. M. JANIK

Institute of Chemistry of the Jagiellonian University, 30-060 Kraków, Poland

\author{
K. OTNES
}

Institutt for Atomenergi, $2007 \mathrm{Kjeller,} \mathrm{Norway}$

\begin{abstract}
Résumé. - Des mesures de diffusion quasi-élastique des neutrons ont été effectuées pour les composés nématiques PAA- $\mathrm{d}_{6}$ et PAA- $\mathrm{d}_{8}$ et analysés en terme de diffusion rotationnelle autour du long axe moléculaire. $\tau_{1}$, temps de corrélation rotationnel, a été estimé à $4 \mathrm{ps.} \mathrm{Cette} \mathrm{valeur} \mathrm{n'est}$ pas en accord avec le temps de relaxation diélectrique qui est égal à 20 ps. Une telle différence peut provenir du type de réponse mis en jeu : la méthode des neutrons conduit à une réponse monomoléculaire alors que les mesures diélectriques reflètent des propriétés coopératives. D'un autre point de vue ce désaccord pourrait indiquer que le modèle de diffusion rotationnel est trop simple. Quelques conclusions sont données concernant la diffusion translationnelle dans le PAA et la rotation des groupes méthyles.
\end{abstract}

\begin{abstract}
Quasielastic neutron scattering experiments carried out for nematic $d_{6}-P A A$ and $\mathrm{d}_{8}$-PAA were analysed by using the rotational diffusion around the long molecular axis model. The $\tau_{1}$ rotational correlation time was estimated for a $4 \mathrm{ps}$. This value does not agree with the dielectric relaxation time which equals to $20 \mathrm{ps}$. Such disagreement may be a reflection of differences in the type of response : the neutron method leads to a monomolecular response, whereas dielectric measurements reffect bulk properties. On the other hand the above disagreement may be an indication that the model of rotational diffusion is too simple. A few conclusions concerning the translatory diffusion in PAA, and also the methyl groups rotation are made.
\end{abstract}

1. Introduction. - The incoherent quasi-elastic neutron scattering technique (QNS) may provide information concerning the stochastic motions of molecules if the correlation times of these motions are of the order of $10^{-11}-10^{-12} \mathrm{~s}$. The sensitivity of the QNS technique to detailed features of a stochastic motion model is, however, limited, and one must therefore be very careful when claiming that a model has been established on the basis of a model fitting procedure [1]. This paper illustrates it using the experimental data of our previously published work on methyl-deuterated PAA $\left(\mathrm{d}_{6}\right.$-PAA) [2], as well as the newly obtained experimental data on benzene-deuterated PAA $\left(d_{8}-P A A\right)$. The experimental technique and the data processing procedure were described in paper [2].

2. Does a rotational diffusion around the long molecular axis explain the QNS spectra ? - The answer of paper [2] to this question is no. This is depicted in figure 1 , which for oriented nematic $\mathrm{d}_{6}$-PAA (and a scattering angle of e.g. $40^{\circ}$ ), shows a rather unsatisfactory fit of a model (a) assuming a rotational diffusion kind of reorientation, with a adjustable

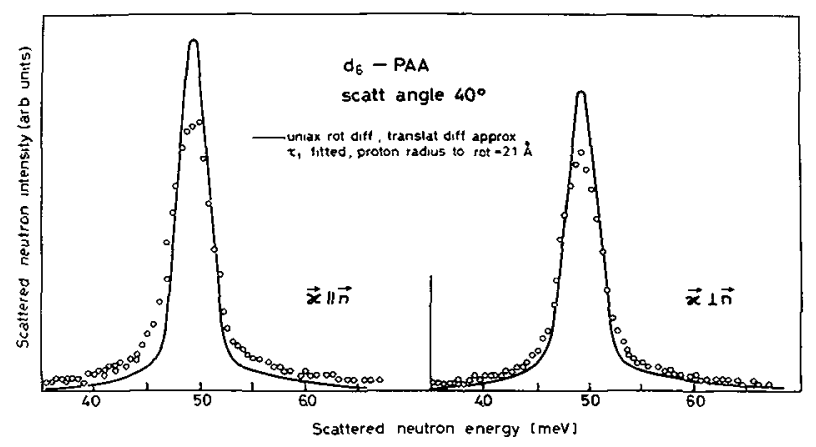

FIG. 1. - Comparison of model (a) with the QNS data for nematic $d_{6}$-PAA. 
correlation time $\tau_{1}\left({ }^{1}\right)$. As discussed in [2], the competing stochastic process, in this case the translatory diffusion, was taken into account only as an intensityreducing factor of the Debye-Waller type. The amount of reduction in intensity was deduced from the Lorentzian width (FWHM) equal to $2 \hbar D_{\|} \kappa^{2}$ or $2 \hbar D_{\perp} \kappa^{2}$ for the $\boldsymbol{\kappa} / \mathbf{n}$ and the $\boldsymbol{\kappa} \perp \mathbf{n}$ geometry, respectively. (Here $D_{\|}=5.5 \times 10^{-6} \mathrm{~cm}^{2} \mathrm{~s}^{-1}$

and

$$
D_{\perp}=3.4 \times 10^{-6} \mathrm{~cm}^{2} \mathrm{~s}^{-1}
$$

are the corresponding translatory diffusion coefficients [3]. $\hbar \kappa$ is the neutron momentum transfer and $\mathbf{n}$ is the nematic director.) A positive aspect of model (a) is that $\tau_{1}$ is constant (within the error limits) over the whole range of scattering angles $\left(20^{\circ}-60^{\circ}\right)$ studied both for $\boldsymbol{\kappa} / / \mathbf{n}$ and $\boldsymbol{\kappa} \perp \mathbf{n}$. The average value of $\tau_{1}$ equals to $1.1 \mathrm{ps}$. The unsatisfactory character of model (a) is illustrated by a large value of the statistical test parameter $\chi^{2}(73)$. One reason for this is certainly that the translatory diffusion has not been taken into account properly. We now try to improve the model by making a convolution of the translatory Lorentzian (FWHM equal to $2 \hbar D_{\|} \boldsymbol{\kappa}^{2}$ or $2 \hbar D_{\perp} \kappa^{2}$ ) with the rotational diffusion scattering law (model (b)). The results for the experimental data for $d_{6}$-PAA are presented in figures 2 and 3 . The quality of the fit is now satis-

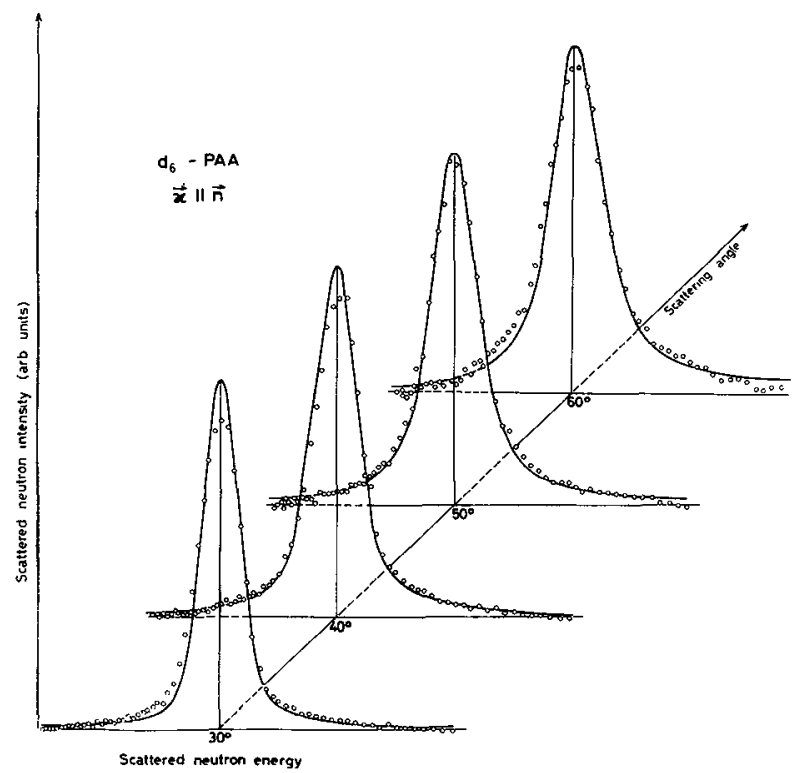

FIG. 2. - QNS data and the model fittings for $d_{6}-P A A$ in the nematic phase, $\mathbf{\kappa} / / \mathbf{n}$, for the scattering angles $30,40,50$ and $60^{\circ}$.

factory $\left(\chi^{2}=8\right)$ but $\tau_{1}$ now seems to depend both on the scattering angle, and what is worse, on whether we measure for $\boldsymbol{k} / / \mathbf{n}$ or $\mathbf{k} \perp \mathbf{n}$ (Table I). We therefore believe that a reorientation only around the long molecular axis is a too simplified picture for

(1) The formulae are given in paper [2].

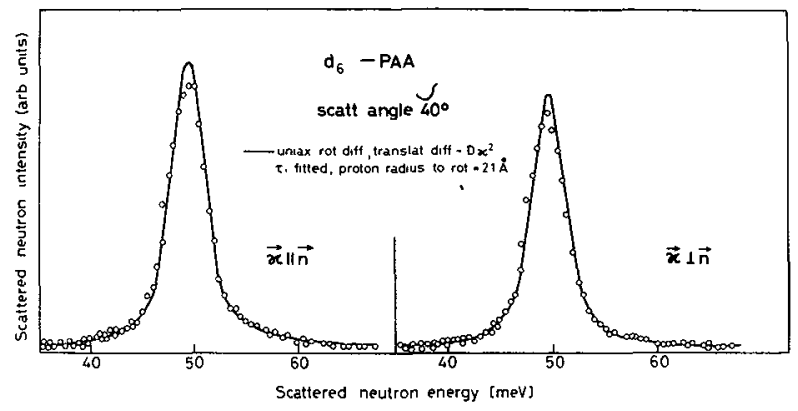

FIG. 3. - Comparison of model (b) with the QNS data for nematic $\mathrm{d}_{6}$-PAA.

\section{TABLE I}

Values obtained for $\tau_{1}$ and $R$ using two different models $((a)$ and $(b))$ for describing the molecular reorientations in nematic $\mathrm{d}_{6}-\mathrm{PAA} . \tau_{1}$ is the rotational correlation time for the rotational diffusion around the long molecular axis of inertia (ps). $R$ is the radius of the reorienting protons $(\AA)$

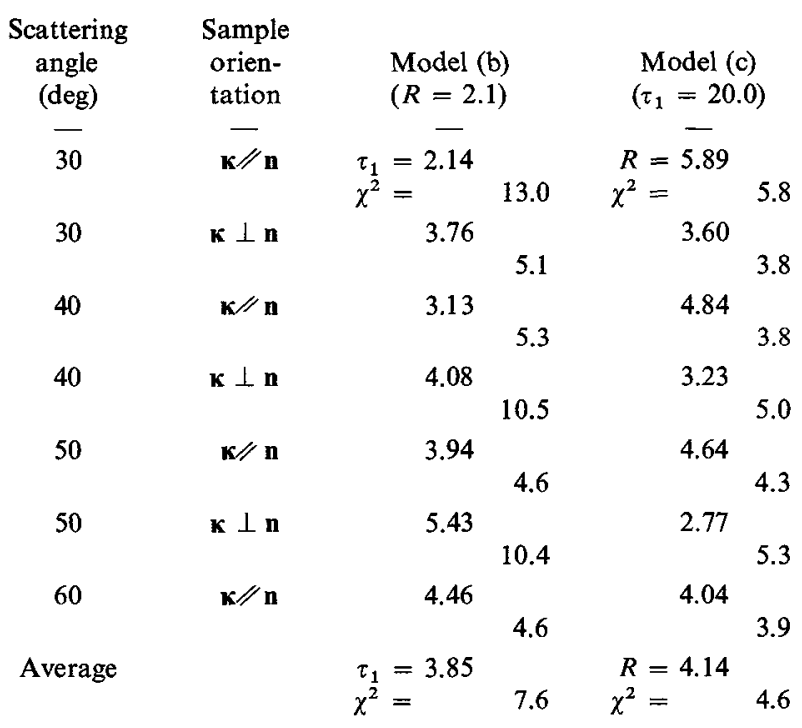

explaining the QNS spectra. On the other hand we want to point out the good agreement between the average value of $\tau_{1}$ (3.9 ps) obtained using model (b) with that obtained in a QNS experiment with larger $\kappa$-values [4], where $\tau_{1}$ amounts to $3.7 \mathrm{ps}$.

3. Can we provide any new information about the translatory diffusion ? - It seems that an apparent increase of $\tau_{1}$ with increasing scattering angle, as observed in model (b) (Table I), can be explained by a shortcoming of the continuous translatory diffusion scattering law for large $\kappa$-values. In fact, the width $\left(\Delta E=2 \hbar D \kappa^{2}\right)$ of the translatory Lorentzian can not increase indefinitely with increasing $\kappa$-values. It must reach a limiting value, as for instance in the jump diffusion model [5]. If this is so, the applied $2 \hbar D \kappa^{2}$-correction is too large and hence the reorientational contributions are apparently too small. 
This effect increases with increasing scattering angle. Therefore, the apparent variation of $\tau_{1}$ with the scattering angle corroborates the hypothesis that the validity of the continuous translatory diffusion model in this case is dubious.

4. Are the director fluctuations affecting our QNS spectra ? - The suspicion that model (b) is too simple is supported by the discrepancy between our value of $\tau_{1}$ and that determined in the dielectric relaxation measurements, which gave $\tau_{1}=20$ ps for nematic PAA [6]. Of course, to a certain point, it may be due to the fact that the QNS technique gives a single molecular response, whereas in the dielectric measurements one measures the bulk properties. We feel, however, that the difference should not be so great. It is therefore tempting to keep $\tau_{1}$ constant and equal to $20 \mathrm{ps}$ (the dielectric value) and vary another parameter in the model. The only possibility is to vary the radius of the reorienting protons which in the models (a) and (b) were set equal to $2.1 \AA$. In these models the assumption is that the reorientation takes place around the long axis. If this radius now is adjustable (model (c)), one obtains the best fits for a value of about $4 \AA$. An example of such fits is shown in figure $4\left(\chi^{2}=5\right)$ (Table I).

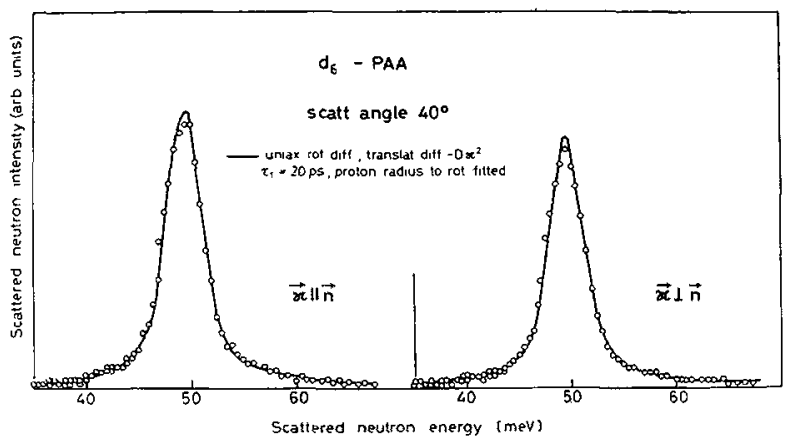

FIG. 4. - Comparison of model (c) with the QNS data for nematic $\mathrm{d}_{6}$-PAA.

This may indicate that the reorientation around the long axis is not the only fast motion, but that the molecules reorient with a much larger effective radius. A hypothetical picture could be this : the molecules, when reorienting, perform at the same time a kind of fast precession around the director $\mathbf{n}$. The two motions are strongly coupled and we can therefore speak about an effective correlation time and an effective proton radius.

If this is so, we should expect an increase of this syndrome when passing from methyl deuterated PAA to benzene deuterated PAA. In $d_{8}$-PAA the neutron will predominantly reflect the motion of the methyl protons which are located in the terminals of the molecule. The neutron spectra will therefore mainly contain information about the fast reorientational motion. It is obvious that we should also take into account the fast rotation of the methyl groups around their CO-axis when fitting the $\mathrm{d}_{8}$-PAA data. This is done in the same way as in paper [2] (see also Section 5 of this paper). Figure 5 shows (for $\mathbf{k} / / \mathbf{n}$ )

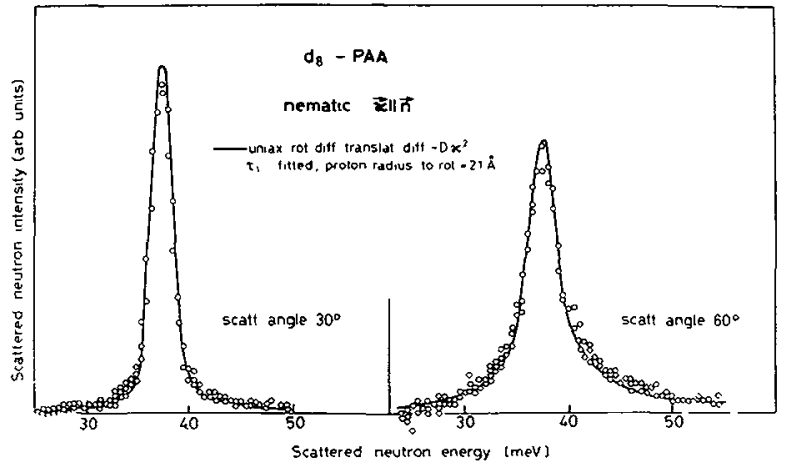

FIG. 5. - Comparison of the model described in sec. 5 with the QNS data for $d_{8}$-PAA in the nematic phase $\left(\tau_{1}\right.$ fitted).

the results of the fittings for nematic $d_{8}$-PAA for $30^{\circ}$ and $60^{\circ}$ scattering angles. The trial with $\tau_{1}$ and $\tau_{\mathrm{CH}_{3}}$ taken as adjustable parameters and the radius of the reorienting protons fixed $(2.1 \AA)$, gives (see Table II) a $\tau_{1}$ which is consistant with that for $d_{6}-$ PAA $\left(\tau_{1}=2 \mathrm{ps}\right)$. On the other hand, when the correlation time $\tau_{1}$ is fixed to the dielectric value of $20 \mathrm{ps}$, the manipulation with the effective proton radius gives also good quality fits for both angles with an optimal effective radius of $6 \AA$ (Fig. 6, Table II), i.e. larger than for $d_{8}$-PAA. In general this is consistant with the idea that the terminals should feel the complex character of the fast reorientational motion more pronounced.

\section{TABLE II}

Values obtained for $\tau_{1}, R$ and $\tau_{\mathrm{CH}_{3}}$ using the model put forward in sec. 5 to describe the molecular reorientation in nematic $\mathrm{d}_{8}-\mathrm{PAA}(\boldsymbol{\kappa} / / \mathbf{n}) . \tau_{1}$ is the correlation time for the rotational diffusion around the long molecular axis of inertia (ps). $R$ is the radius of the reorienting protons $(\AA) . \tau_{\mathrm{CH}_{3}}$ is the average time between $120^{\circ}$ jumps of the $\mathrm{CH}_{3}$-group (ps)

$$
\begin{aligned}
& \text { Scattering } \quad R=2.1 \AA \\
& \text { angle (deg) } \quad \tau_{1} \text { fitted } \\
& \tau_{1}=1.81 \mathrm{ps} \\
& 30 \\
& \begin{aligned}
\tau_{{ }^{\mathrm{CH}_{3}}} & =2.37 \mathrm{ps} \\
\chi^{2} & =5.5
\end{aligned} \\
& \tau_{1}=2.35 \mathrm{ps} \\
& \tau_{\mathrm{CH}_{3}}=3.45 \mathrm{ps} \\
& \begin{array}{c}
\tau_{1}=20 \mathrm{ps} \\
R \text { fitted }
\end{array} \\
& \chi^{2}=6.1 \\
& \begin{aligned}
R & =6.66 \AA \\
\tau_{{ }^{\mathrm{CH}_{3}}} & =1.33 \mathrm{ps} \\
\chi^{2} & =3.9 \\
R & =5.82 \AA \\
\tau_{\mathrm{CH}_{3}} & =3.92 \mathrm{ps} \\
\chi^{2} & =5.3
\end{aligned}
\end{aligned}
$$

It should be pointed out, however, that the minima of $\chi^{2}$ are rather shallow in all the fittings, and the uncertainty in the determined value of $\tau_{1}$ or the radius of the reorienting protons is therefore large. It is our feeling that some of these uncertainties are 
due to a possible non-applicability of the convolution approximation as the various modes of motion of the protons may not be independent [7]. The uncertainty in $\tau_{1}$ may quite possibly amount to about $100 \%$, which makes the gap between the QNS and the dielectric relaxation data not so very drastic and the conclusions less safe.

5. Is the internal rotation of the methyl groups visible ? - It was suggested in [2] that the $\mathrm{CH}_{3}$ rotation can be observed by comparing the QNS results for normal PAA with those for $d_{6}$-PAA. There we made a convolution of the experimental scattering law for $d_{6}$-PAA with a theoretical scattering law for the internal rotation of the methyl groups where the protons made $120^{\circ}$ jumps. In this way it was possible to obtain the time between successive jumps, $\tau_{\mathrm{CH}_{3}}$, in nematic PAA. We got $\tau_{\mathrm{CH}_{3}}=1.4 \mathrm{ps}$.

It seems obvious that the effect of the $\mathrm{CH}_{3}$-rotation should be enhanced for $d_{8}$-PAA. In the fitting procedure presented in figure 5 (see also Table II) the scattering law for each proton was a convolution of three contributions : the translatory diffusion in the continuous diffusion approximation, the rotational diffusion of the molecule $\left(\tau_{1}\right)$ and the $\mathrm{CH}_{3}$-rotation $\left(\tau_{\mathrm{CH}_{3}}\right)$. The $\tau_{\mathrm{CH}_{3}}$-value obtained in this way is equal to about $3 \mathrm{ps}$, giving a rather good agreement with the result of [2].

It is worthwhile to point out that the $\mathrm{CH}_{3}$-rotation survives the freezing of $\mathrm{d}_{8}$-PAA (Fig. 7). The obtained $\tau_{\mathrm{CH}_{3}}$-value is about 7 ps. This agrees well with the previously published QNS data for solid PAA [8] where $\tau_{\mathbf{C H}_{3}}$ was determined to be $9 \mathrm{ps}$, and also with the NMR relaxation data for solid PAA [9] which gave $\tau_{\mathrm{CH}_{3}}$ equal to $5.1 \mathrm{ps}$.

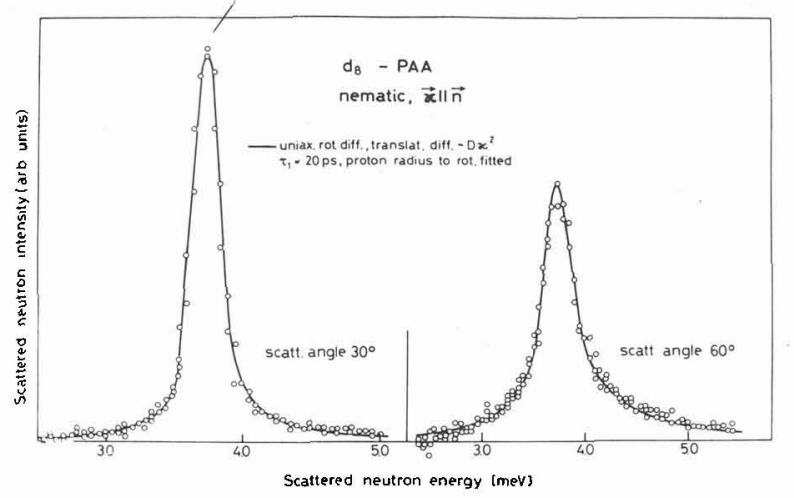

Fig. 6. - Comparison of the model described in sec. 5 with the QNS data for $d_{8}$-PAA in the nematic phase ( $R$ fitted).

6. Conclusions. - A critical comparison of the results obtained for $d_{6}$-PAA and $d_{8}$-PAA using the quasielastic neutron scattering technique leads to the following conclusions :

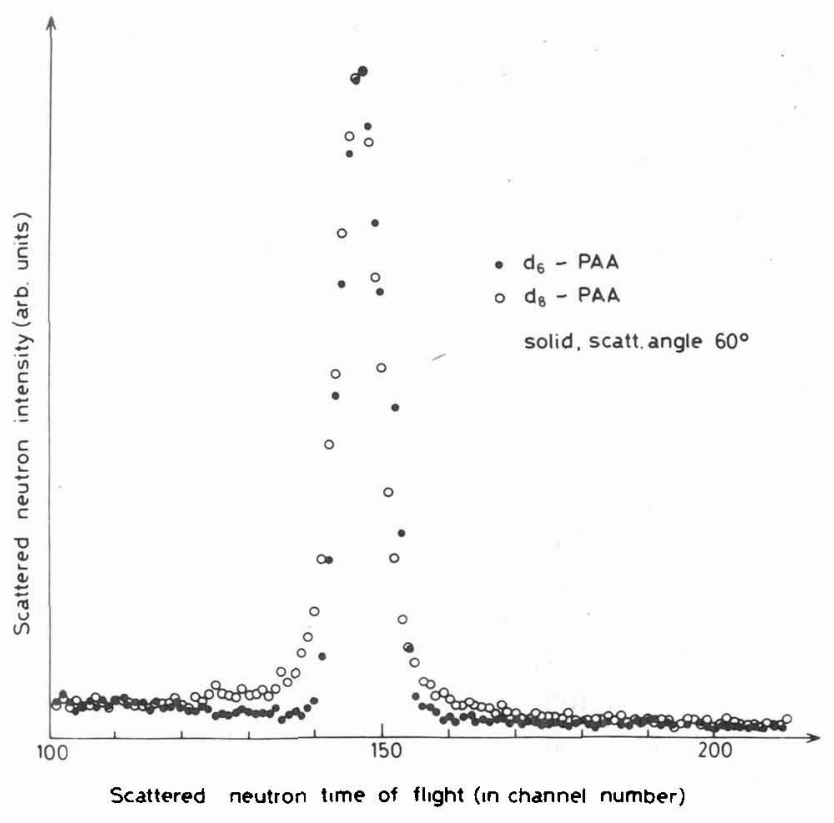

FIG. 7. - QNS data for $d_{6}-P A A$ and $d_{8}-P A A$ in the solid phase for a scattering angle of $60^{\circ}$.

1. The simple rotational diffusion around the long molecular axis is not describing the QNS spectra sufficiently well. A distinct tendency of a variation of $\tau_{1}$ (reorientational correlations time) with the scattering angle, slightly different $\tau_{1}$ values obtained for $\boldsymbol{\kappa} \| \mathbf{n}$ and $\boldsymbol{\kappa} \perp \mathbf{n}$ and a disagreement between the $\tau_{1}$ values obtained from QNS and the dielectric relaxation measurements, are the syndrome of the above mentioned inadequacy.

2. The above mentioned variation in $\tau_{1}$ with scattering angle may be removed by assuming that the translatory diffusion of the molecules is not a continuous diffusion and hence posseses a jump character.

3. If one accepts the dielectric value of $\tau_{1}$ one obtains from QNS a larger effective radius of the reorienting protons which may perhaps be understood as an indication of a complex character of the reorientational motion, for instance, the reorienting molecules perform at the same time a kind of fast precession around the director $\mathbf{n}$.

4. The internal $\mathrm{CH}_{3}$-rotation is clearly visible in the QNS spectra for nematic $\mathrm{d}_{8}$-PAA and solid $\mathrm{d}_{8}$-PAA.

Acknowledgments. - Our thanks are due to Dr. Tormod Riste from Institutt for atomenergi, Kjeller, Norway, for his interest and discussions. The two of us (J. A. J. and J. M. J.) are grateful to the Norwegian Council for Scientific and Industrial Research for financial support during the stay in Norway. 


\section{References}

[1] JANIK, J. A., in print in Acta Phys. Pol. A 54 (1978) 513.

[2] JaniK, J. A., JaniK, J. M., Otnes, K., KrawczyK, J., RosciszEWSKI, K., Physica 92B (1977) 351.

[3] Tópler, I., Alefeld, B., Springer, T., Mol. Cryst. Liq. Cryst. 26 (1974) 297.

[4] Nimura, N., BJerRum Moller, H., Riste, T., to be published.

[5] Singwi, K. S., Sjolander, A., Phys. Rev. 119 (1960) 863.
[6] Wróbel, S., Janik, J. A., Moścłcki, J. K., Urban, S., Acta Phys. Pol. A 48 (1975) 215.

[7] Berne, B. J., Montgomery, J. A. Jr., Mol, Phys. 32 (1976) 363.

[8] Hervet, H., Dianoux, A. J., Lechner, R. E. and Volino, F., J. Physique Lett. 35 (1977) L-151.

[9] Samulski, E. T., Dybowski, C. R., Wade C. G., Phys. Rev. Lett. 29340 (1972) 1050. 